Western North American Naturalist 69(2), () 2009, pp. 165-170

\title{
SELECTIVE HERBIVORY BY THE DESERT WOODRAT (NEOTOMA LEPIDA) ON JOSHUA TREES (YUCCA BREVIFOLIA)
}

\author{
Monte P. Sanford ${ }^{1,2}$ and Nancy Huntly ${ }^{1}$
}

\begin{abstract}
We studied herbivory by the desert woodrat (Neotoma lepida) on Joshua trees (Yucca brevifolia) in the Mojave Desert to determine whether N. lepida fed selectively based on leaf nitrogen content. We measured leaf nitrogen content and the location and amount of herbivory by woodrats on Y. brevifolia trees in southwestern Utah, USA. Neotoma lepida removed the outer tips of leaves (1/3 to $2 / 3$ of total leaf length) but left leaf bases, which had lower nitrogen content, uneaten. Herbivory by N. lepida also was concentrated on rosettes that were oriented south, and these had significantly higher nitrogen content than rosettes that were oriented north. Finally, N. lepida fed more on trees that had higher mean leaf nitrogen contents. Thus, $N$. lepida selectively foraged among leaf parts, among rosettes of leaves, and among trees of $Y$. brevifolia, and disproportionate foraging was correlated with nitrogen content of leaves.
\end{abstract}

Key words: desert woodrat, herbivory, Joshua tree, Neotoma lepida, nitrogen, Yucca brevifolia.

Animals require nitrogen in their diets because nitrogen is a component of proteins and cellular structures that are essential for metabolic processes (Mattson 1980). Limited nitrogen supplies in desert ecosystems result in low levels of nitrogen in desert plants (Garcia-Moya and McKell 1970, Sharifi et al. 1988), which may present a substantial problem for desert herbivores. Herbivores are comprised of 10-20 times more nitrogen than autotrophs (Mattson 1980, Elser et al. 2000), and desert herbivores must obtain sufficient nitrogen to sustain themselves from a diet of nitrogen-poor desert plants. The acquisition of sufficient nitrogen is known to result in nitrogen-selective feeding in many herbivore species (Mattson 1980, Huntly 1991). For example, grouse, hares and rabbits (Miller 1968), rodents (Snyder 1992, Torres-Contreras and Bozinovic 1997), monkeys (Milton 1979), and koalas (Moore and Foley 2005) feed selectively on nitrogen-fertilized vegetation or on plants or plant parts that contain more nitrogen.

Nitrogen is an essential element of photosynthetic enzymes, and nitrogen concentrations of plants or plant parts tend to be strongly correlated with photosynthetic capacity (Field and Mooney 1986, Evans 1989). Thus, disproportionate allocation of nitrogen to particular tissues or regions can significantly improve the overall photosynthetic performance of a plant.
An example is the arborescent desert monocot Yucca brevifolia, the Joshua tree, which allocates more nitrogen to plant parts that have higher potential for photosynthesis (Rasmuson et al. 1994). Joshua trees have branches that terminate in rosettes of long-lived woody leaves, and both branches and rosettes are oriented disproportionately to the south, with an average azimuth of $163^{\circ}$ at our study area in southwestern Utah (Fig. 1A). This orientation increases interception of sunlight during times of the year favorable for photosynthesis, and trees allocate more nitrogen to leaves within south-facing rosettes than to those within northfacing rosettes (Rasmuson et al. 1994).

We studied herbivory by the desert woodrat, Neotoma lepida, on the Joshua tree and asked whether herbivory by woodrats was correlated with nitrogen content of Joshua tree plants or plant parts. Woodrats (genus Neotoma) feed on many species of desert plants that are unpalatable to most herbivores and that often contain chemical defenses, such as phenolic resins, alkaloids, and terpenes (Meyer and Karasov 1989, Sorenson et al. 2005). The desert woodrat feeds on Joshua trees in parts of the Mojave Desert (Lee 1963, Chess and Chew 1971), and we observed herbivory by woodrats on Joshua trees within our study area, both directly and as evidenced by their distinctive bite marks on leaves. We hypothesized that woodrats would

${ }^{1}$ Department of Biological Sciences, Idaho State University, Pocatello, ID 83209-8007.

${ }_{2}^{2}$ Present address: Department of Biology, University of Nevada, Reno, Mailstop 315, Reno, NV 89557. E-mail: monte.sanford@gmail.com 


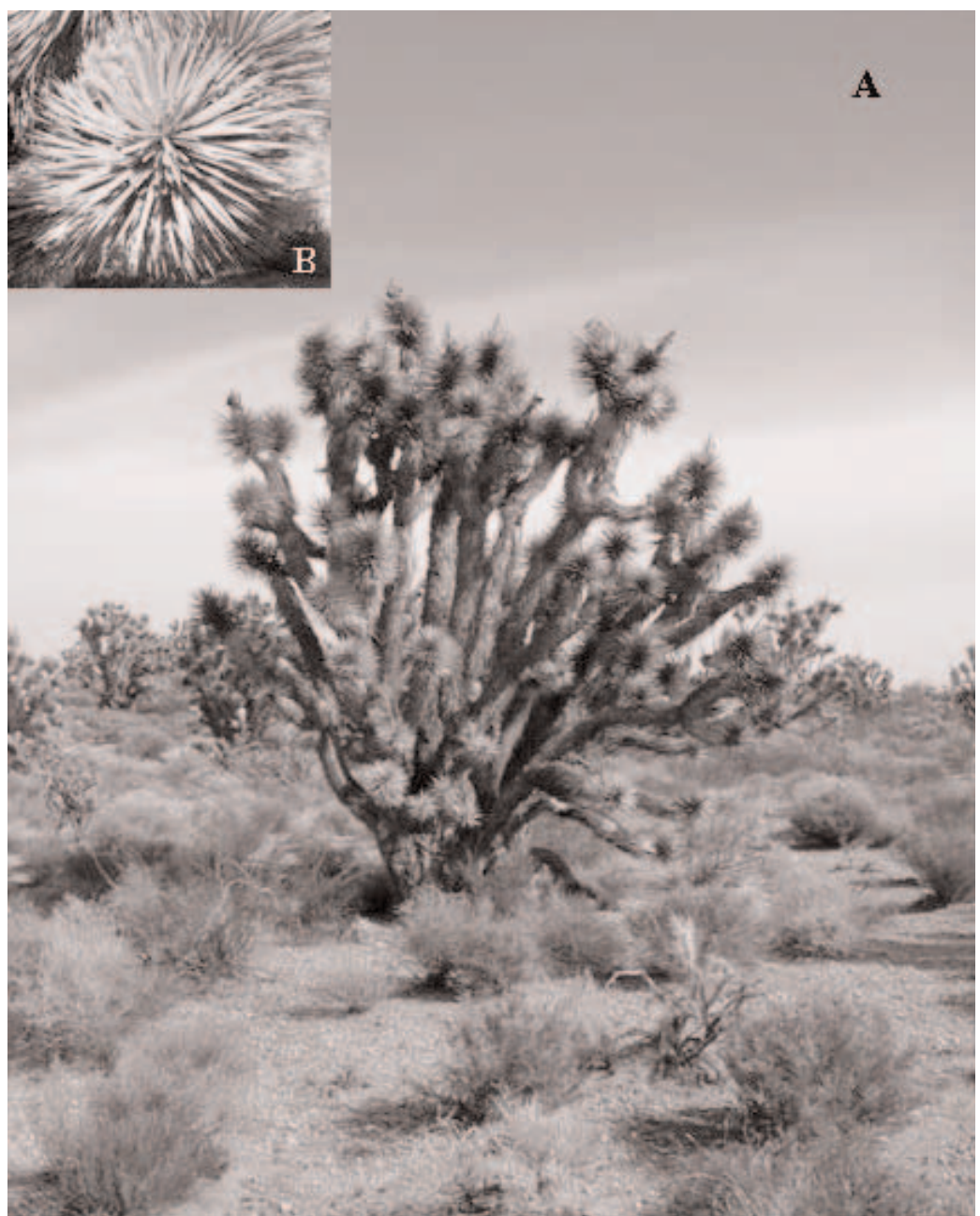

Fig. 1. A, mature Joshua tree at Lytle Preserve, Utah, with most branches oriented south; B, rosette of leaves of a Joshua tree showing herbivory by Neotoma lepida.

consume a higher proportion of leaves from south-facing rosettes, reflecting the leaves' higher nitrogen content, and that other disproportionate herbivory by woodrats would also reflect differences in nitrogen content. We tested for selective foraging between portions of individual leaves (tip vs. base), between north and south-facing rosettes within Joshua tree crowns, and among trees within Joshua tree woodland.

\section{Methods}

We studied herbivory by the desert woodrat at Brigham Young University's Lytle Preserve, $48 \mathrm{~km}$ west of St. George, Utah, in the north- eastern Mojave Desert (elevation $860 \mathrm{~m}$ ). Average annual temperature and precipitation at St. George are $16.5^{\circ} \mathrm{C}$ and $210 \mathrm{~mm}$, respectively. Extensive Y. brevifolia woodlands grow on benches above the floodplain of Beaver Dam Wash, where they co-occur with other dominant plant species including, in rank order of abundance, Coleogyne ramosissima, Ambrosia dumosa, Larrea tridentata, Krameria grayi, and Thamnosma montana (Gilliland et al. 2006).

We measured leaf nitrogen content and herbivory by woodrats from two 100-m belt transects that were located along the edges of 2 benches, sampling the 22 trees within these transects that had signs of herbivory by 
TABLE 1. Mean percent nitrogen content (95\% CI) for tips and bases of leaves of Joshua trees in the Mojave Desert, Utah.

\begin{tabular}{lcc}
\hline Leaf comparison & Percent nitrogen & $P$ \\
\hline Base of eaten leaf & $0.801(0.784-0.818)$ & 0.428 \\
Base of uneaten leaf & $0.772(0.754-0.799)$ & $<0.001$ \\
Tip of uneaten leaf & $1.302(1.262-1.342)$ & \\
North & $0.894(0.873-0.915)$ & \\
South & $1.043(0.986-1.100)$ & $<0.01$ \\
\hline
\end{tabular}

woodrats. Herbivory was apparent because desert woodrats removed leaves from rosettes, leaving behind leaf bases with distinctively chewed ends (Fig. 1B). All 22 trees were sampled in March 1999, and 20 trees were resampled in September 1999 and September 2000.

Leaf nitrogen was measured at the CERE Analytical Lab (Idaho State University, Pocatello, ID), where leaf samples were dried for 14 days at $55{ }^{\circ} \mathrm{C}$, ground with a Wiley mill, and analyzed in triplicate for nitrogen content with a Fisons model NC1500 elemental analyzer. Samples that were collected at the 3 different times did not differ significantly in percent nitrogen content according to a one-way ANOVA with Bonferroni corrections (all $P>0.23$ ).

Neotoma lepida invariably consumed only the distal end (the tip) of leaves of Joshua trees, so we compared leaf nitrogen content between tips and bases of uneaten leaves and between bases of uneaten leaves and remaining bases of eaten leaves. In March 1999 we sampled bases of eaten leaves by selecting 3 remaining bases from each rosette that had $N$. lepida herbivory. In September 1999, we sampled uneaten leaf tips and bases by selecting one mature leaf of the southernmost rosette of each tree. Leaves were separated to base and tip based on the average length left uneaten by Neotoma, which was $3 \mathrm{~cm}$ (range $2-4 \mathrm{~cm}$ ). Using trees as experimental units, we used one-way ANOVA followed by Bonferroni-corrected pairwise contrasts of the leaf categories to test for differences in percent leaf nitrogen content between tips and bases of uneaten leaves and between uneaten leaf bases and remaining bases of eaten leaves.

We also compared herbivory and leaf nitrogen between north-facing and south-facing rosettes of the same tree. We divided each of the 20 trees sampled in September into 4 cardinal quadrants (NW, NE, SE, SW) and counted the number of rosettes with and without $N$. lepida herbivory in each quadrant. We used a $2 \times 4$ chi-square contingency analysis to test whether the proportion of rosettes with herbivory varied among cardinal quadrants. We tested for differences in percent nitrogen using a paired-sample $t$ test with tree as the experimental unit.

Finally, we compared the number of rosettes from which woodrats had removed leaves with the mean nitrogen content of leaves of each tree. We averaged percent nitrogen values of 3 uneaten, mature leaves from up to 10 rosettes of each tree sampled in September 2000. For trees that had more than 10 rosettes with woodrat herbivory, we randomly selected 10 rosettes for nitrogen analysis; for trees that had 10 or fewer rosettes with woodrat herbivory, we analyzed all rosettes for nitrogen. We square-root transformed the response variable to improve homogeneity of variance. Using linear regression with tree as the experimental unit, we then tested whether average leaf nitrogen predicted the amount of herbivory (proportion of rosettes with herbivory).

\section{RESULTS}

Neotoma lepida fed primarily on the distal tips of Yucca brevifolia leaves, removing them and leaving the leaf bases. Nitrogen content differed significantly among uneaten tips and bases of eaten and uneaten leaves $\left(F_{2,21}=\right.$ 83.455, $P<0.001$; Table 1). Uneaten leaf tips contained significantly more nitrogen than either uneaten leaf bases $(P<0.001)$ or the remaining bases of eaten leaves $(P<0.001)$.

Neotoma lepida fed selectively among leaf rosettes within Yucca trees. The proportion of rosettes with herbivory varied significantly among cardinal quadrants $\left(\chi^{2}=16.67, \mathrm{df}=3\right.$, $P<0.001$; Table 2). Woodrats had eaten almost twice the proportion of rosettes from SW and SE quadrants $(16.6 \%)$ as from NW and NE quadrants $(9.8 \%)$. Nitrogen content of leaves from south-facing rosettes was significantly greater than that of north-facing rosettes by an average of $17 \%(t=3.138, \mathrm{df}=21, P=0.005)$.

Neotoma lepida also fed disproportionately on trees that had higher nitrogen content. The number of rosettes with herbivory by woodrats 
TABLE 2. Numbers of eaten and uneaten rosettes from quadrants (southeast $[\mathrm{SE}]$, southwest $[\mathrm{SW}]$, northwest $[\mathrm{NW}]$, and northeast [NE]) of 20 Joshua trees in the Mojave Desert, Utah.

\begin{tabular}{lcccc}
\hline & \multicolumn{4}{c}{ Tree quadrant } \\
\cline { 2 - 5 } Rosette type & $\mathrm{SE}$ & $\mathrm{SW}$ & $\mathrm{NW}$ & $\mathrm{NE}$ \\
\hline Uneaten rosettes & 576 & 561 & 253 & 264 \\
Eaten rosettes & 124 & 103 & 26 & 30 \\
Proportion eaten & 0.18 & 0.16 & 0.09 & 0.1 \\
\hline
\end{tabular}

increased significantly with average leaf nitrogen content of a tree $\left(r^{2}=0.363, \mathrm{df}=19, P=\right.$ 0.003; Fig. 2). Average leaf nitrogen ranged from $0.81 \%$ to $1.21 \%$, so the most nitrogenrich trees had about $30 \%$ higher nitrogen content than the least nitrogen-rich trees.

\section{Discussion}

Neotoma lepida foraged selectively on $Y$. brevifolia trees at 3 levels, all correlated with significant differences in plant nitrogen content. First, $N$. lepida selectively consumed leaf tips, which contained about $70 \%$ more nitrogen than did leaf bases. Joshua trees apparently allocated more nitrogen to leaf tips, which receive more direct solar radiation than the more-shaded bases and thus should have higher photosynthetic potential. Our data suggest that $N$. lepida detected these intraleaf differences in nitrogen.

Neotoma lepida also fed selectively among rosettes within trees, feeding disproportionately more on south-facing rosettes. Eighty percent of feeding by woodrats was on southfacing rosettes (those with azimuths from $120^{\circ}$ to $270^{\circ}$ ). In addition, the proportion of rosettes with herbivory was almost twice as high in SE and SW quadrants of Joshua trees.

Uneaten leaves from rosettes that had some leaves eaten by woodrats had higher nitrogen $(1.44 \%)$ than either mature leaves $(1.04 \%)$ or southerly leaves from rosettes without herbivory $(1.04 \%)$, which could imply that woodrats feed on the more nitrogen-rich leaves of the southerly rosettes of Joshua trees (Table 1). However, an alternative interpretation is that leaf nitrogen content increases locally after browsing, since herbivory often does alter plant chemistry and nutritional quality (Huntly 1991, Tallamy and Raupp 1991). The potential effect of herbivory on $Y$. brevifolia is unknown, and we did not test whether herbivory by woodrats caused local increase in tissue nitrogen content; but, if local nitrogen induction does occur, then woodrats might acquire more dietary nitrogen by foraging repeatedly at the same trees and rosettes.

Finally, N. lepida fed selectively among individual Joshua trees, consuming more from trees that had higher nitrogen. Our data suggest that $N$. lepida can detect differences among trees that have mean nitrogen levels from $0.81 \%$ to $1.21 \%$. Other small herbivores discriminate among foods that differ, even slightly, in the content of significant dietary nutrients. For instance, the eastern woodrat (Neotoma floridana) can distinguish foods that differ from $5 \%$ to $20 \%$ in lipid composition and quickly distinguish between foods with similar low $(<5 \%)$ protein levels (Post 1993). Other herbivores also disproportionately feed from particular trees (e.g., Milton 1979), and Stephens' woodrats preferentially feed from certain juniper trees (Vaughn 1982). Although these studies did not correlate selective feeding with nitrogen content, Milton (1979) suggested that nitrogen balance was an important component in selective feeding by howler monkeys.

It is possible that factors other than the nitrogen contents we measured are responsible for the selective feeding by woodrats that we observed. First, Joshua trees may contain plant secondary metabolites (PSMs) that influence woodrat herbivory. Many herbivores feed selectively with respect to PSMs (e.g., Meyer and Karasov 1989, Lawler et al. 2000, Moore et al. 2005), and woodrats in the Great Basin feed selectively in response to PSMs within juniper trees (e.g., Sorenson et al. 2005). We did not measure PSMs and we found no literature describing the PSMs of Joshua trees, although Sorensen et al. (2005) stated that yuccas do not contain phenolics. If PSMs were directly selected or avoided by woodrats, then PSMs and nitrogen would likely play concomitant roles in the feeding patterns we observed, since herbivory by woodrats was positively correlated with tissue nitrogen content. There are documented examples of such concomitant roles of nitrogen and PSMs, for example, herbivory by koalas on Eucalyptus trees (Moore and Foley 2005).

A second alternative is that water content of leaves influences feeding patterns. However, we found little variation in water content between leaf parts, rosettes, or trees, and water content 


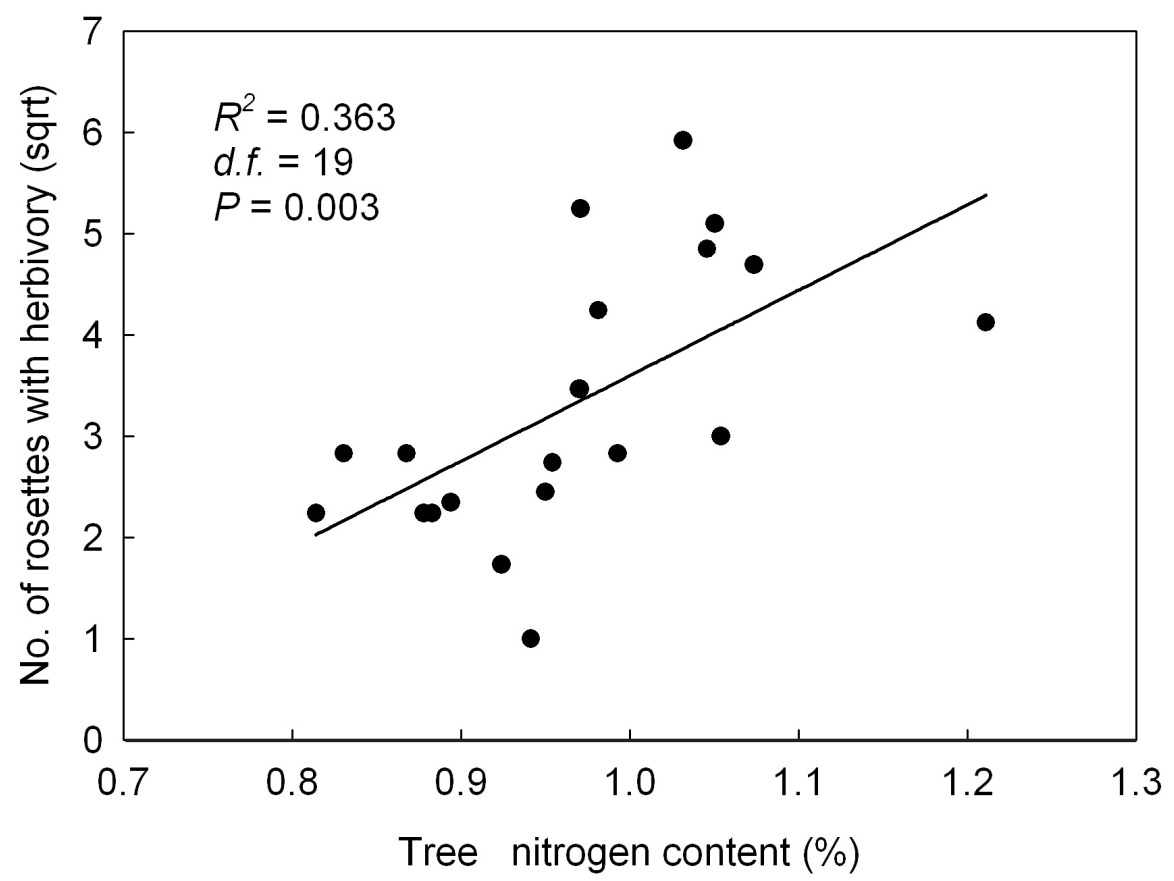

Fig. 2. Relationship between numbers of rosettes fed on by Neotoma lepida and mean leaf nitrogen content for 20 Joshua trees from Lytle Preserve in the Mojave Desert of southwestern Utah.

was not correlated with herbivory by $N$. lepida (Sanford and Huntly unpublished data).

This research clearly demonstrates that $N$. lepida fed selectively among parts of leaves, among rosettes of leaves within tree crowns, and among trees. The selectivity was correlated with differences in leaf nitrogen content, which varied from $17 \%$ to $>200 \%$ difference among plants or plant parts. Thus, the results suggest that $N$. lepida can detect differences between nitrogen contents of plants and plant parts and that nitrogen influences feeding patterns of $N$. lepida on Y. brevifolia in this Mojave Desert ecosystem.

\section{ACKNOWLEDGMENTS}

We thank J.E. Anderson, D. Dearing, J. Denning, J. Fusek, R. Inouye, M. Kreuzer, J. Moodie, K. Rodnick, and S. Vander Wall for field assistance or comments that improved this manuscript. We thank the Monte L. Bean Life Science Museum at Brigham Young University and personnel at the Lytle Preserve for use of facilities. This research was supported by the National Science Foundation (STI9413531).

\section{Literature Cited}

Chess, T., AND R.M. Chew. 1971. Weight maintenance of the desert woodrat (Neotoma lepida) on some natural foods. Journal of Mammalogy 52:193-195.

Elser, J.J., W.F. Fagan, R.F. Denno, D.R. Dobberfuhl, A. Folarin, A. Huberty, S. Interlandi, S.S. Kilham, E. McCauley, K.L. Schulz, et al. 2000. Convergent N:P stoichiometry in freshwater and terrestrial food webs. Nature 408:578-580.

Evans, J.R. 1989. Photosynthesis and nitrogen relationships in leaves of $\mathrm{C}_{3}$ plants. Oecologia 78:9-19.

Field, C., AND H.A. MoOney. 1986. The photosynthesisnitrogen relationship in wild plants. Pages 25-55 in T. Givnish, editor, On the economy of plant form and function. Cambridge University Press, Cambridge.

GarCia-Moya, E., AND C.M. MCKeLL. 1970. Contribution of shrubs to the nitrogen economy of a desert-wash plant community. Ecology 512:81-88.

Gilliland, K.D., N. Huntly, and J.E. Anderson. 2006. Age and population structure of Joshua trees (Yucca brevifolia) in the northwestern Mojave Desert. Western North American Naturalist 66:202-208.

HunTLY, N.J. 1991. Herbivores and the dynamics of communities and ecosystems. Annual Review of Ecology and Systematics 22:477-503.

LaWler, I.R., W.J. Foley, AND B.M. Eschler. 2000. Foliar concentration of a single toxin creates habitat patchiness for a marsupial folivore. Ecology 81:1327-1338.

LEE, A.K. 1963. The adaptations to arid environments of wood rats of the genus Neotoma. University of California Publications in Zoology 64(2):57-96. 
Mattson, W.J., JR. 1980. Herbivory in relation to plant nitrogen. Annual Review of Ecology and Systematics 11:119-161.

Meyer, M.W., and W.H. Karasov. 1989. Antiherbivore chemistry of Larrea tridentata: effects on woodrat (Neotoma lepida) feeding and nutrition. Ecology 70:953-961.

Miller, G.R. 1968. Evidence for selective feeding on fertilized plots by red grouse, hares, and rabbits. Journal of Wildlife Management 3:849-853.

MiLton, K. 1979. Factors influencing leaf choice by howler monkeys: a test of some hypotheses of food selection by generalist herbivores. American Naturalist 114: 362-378.

Moore, B.D., And W.J. Foley. 2005. Tree use by koalas in a chemically complex landscape. Nature 435:488490.

Moore, B.D., W.J. Foley, I.R. Wallis, A. Cowling, And K.A. Handasyde. 2005. Eucalyptus foliar chemistry explains koala feeding preferences. Biology Letters 1:64-67.

PosT, D.M. 1993. Detection of differences in nutrient concentrations by eastern woodrats (Neotoma floridana). Journal of Mammalogy 74:493-497.

Rasmuson, K.E., J.E. Anderson, and N.J. Huntly. 1994. Coordination of branch orientation and photosynthetic physiology in the Joshua tree Yucca brevifolia. Great Basin Naturalist 54:204-211.
Sharifi, M.R., F.C. Meinzer, E.T. Nilsen, P.W. Rundel, R.A. Virginia, W.M. Jarrell, D.J. Herman, and P.C. CLARK. 1988. Effect of manipulation of water and nitrogen supplies on the quantitative phenology of Larrea tridentata (creosotebush) in the Sonoran Desert of California. American Journal of Botany 75: 63-74.

SNYDER, M.A. 1992. Selective herbivory by Abert's squirrel mediated by chemical variability in ponderosa pine. Ecology 73:1730-1741.

Sorenson, J.S., J.D. MCLister, and M.D. Dearing. 2005. Novel plant secondary metabolites impact dietary specialists more than generalists (Neotoma spp.). Ecology 86:140-154.

Tallamy, D.W., and M.J. Raupp, EDitors. 1991. Phytochemical induction by herbivores. John Wiley \& Sons, Inc., New York.

Torres-Contreras, H., and F. Bozinovic. 1997. Food selection in an herbivorous rodent: balancing nutrition with thermoregulation. Ecology 78:2230-2237.

VAughan, T.A. 1982. Stephen's woodrat, a dietary specialist. Journal of Mammalogy 63:53-62.

Received 11 September 2007 Accepted 8 October 2008 